\title{
A Conceptual Framework for Complex Systems at the Crossroads of Food, Environment, Health, and Innovation
}

\author{
Margherita Paola Poto \\ Faculty of Law, UiT The Arctic University of Norway, 9010 Tromsø, Norway; margherita.p.poto@uit.no; \\ Tel.: +47-77623145
}

Received: 26 October 2020; Accepted: 19 November 2020; Published: 20 November 2020

\begin{abstract}
Climate-smart solutions and practices have the potential to contribute to the UN Sustainable Development Goals (SDGs) of achieving zero hunger; ensuring healthy lives and promoting the wellbeing of humans, animals, and plants; reducing ocean overharvesting and overfishing; tackling climate change; driving economic growth; and promoting innovation. Achieving these goals will require searching for, defining, and adopting the most effective and suitable scientific approach for studying synergies between often-opposing socioeconomic and environmental priorities. Developing a critical conceptual framework as a reading key for the SDGs' interactions (theory building) and exploring the possibilities of upscaling successful climate-smart practices, with the case study offered by the SECURE project (theory testing) are the two methods adopted to answer the research hypothesis on the validity and scope of conceptual frameworks for complex systems. The paper concludes with a call for further testing of tools, approaches, and methods to enable dynamic systems thinking to inform upscaling efforts, while recognizing the transdisciplinary nature and complexity of the study of low-trophic marine resources as a constituent of food production, and environmental and health protection systems.
\end{abstract}

Keywords: critical-systems thinking; law; Agenda 2030; climate-smart solutions

\section{Introduction}

Climate-smart solutions [1] to address climate change, achieve sustainable food production and optimal health outcomes for humans, animals, and plants are fraught with obstacles and uncertainties [2] - not least, the fragmentation of research findings, and therefore the difficulty of ensuring their generalizability on the one hand, and of upscaling successful projects and making empiricism meaningful for legal analysis and policy-making, on the other. This chapter explores to what extent a conceptual framework for complex systems identifies, reflects, and helps to achieve UN Sustainable Development Goals (SDGs) in an integrated manner on the one hand, and how such a framework provides an approach for framing, implementing, and upscaling climate-smart practices on the other. I analyze this research hypothesis through two angles: through the hermeneutics of the critical systems theories applied to law, and by assessing whether the elements of a case study (SECURE, UiT The Arctic University of Norway) are compatible with the theories. A conceptual framework that systematizes and problematizes the goals of the Agenda 2030 (in particular, achieving sustainable food production, and protecting and guaranteeing the generalizability and relevance of climate-smart solutions and practices) [3], should help to clarify the interactions between systems (environment, food, health, and innovation), and consequently the various governance arrangements to inform decision-making and implementation [4]. A recent study on the governance of climate-smart agriculture practices notes the need to adopt complex adaptive systems and systems-thinking approaches for 
climate-smart solutions [5], stressing the importance of conceptual frameworks to improve smart and best practices [6]. Conceptually framing climate-smart practices can help to provide a coherent explanation of observed realities, enabling assumptions and logical consequences that can lead to more accurate predictions. Such a conceptual framework of smart practices can set the stage for the generalization of empirical phenomena, in turn making it possible to assess the accuracy of predictions-an essential tool in the scientific approach. The majority of the studies on climate-smart agriculture practices focuses on soil management practices [5], while very little research focuses on the regulatory aspects of climate-smart practices in relation to ocean health [7]. Therefore, this paper addresses a knowledge gap in the need to assist systematic mapping of the Agenda 2030's objectives and in providing empirical testing of the theories with a case study on climate-smart agricultural practices applied to the ocean (Figure 1).

\section{Knowledge gaps}

- Lack of systematic mapping of Agenda 2030

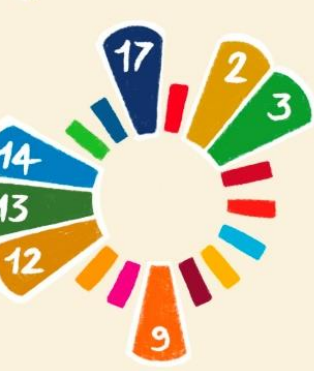

- Limited research on CSA applied to the OCEAn
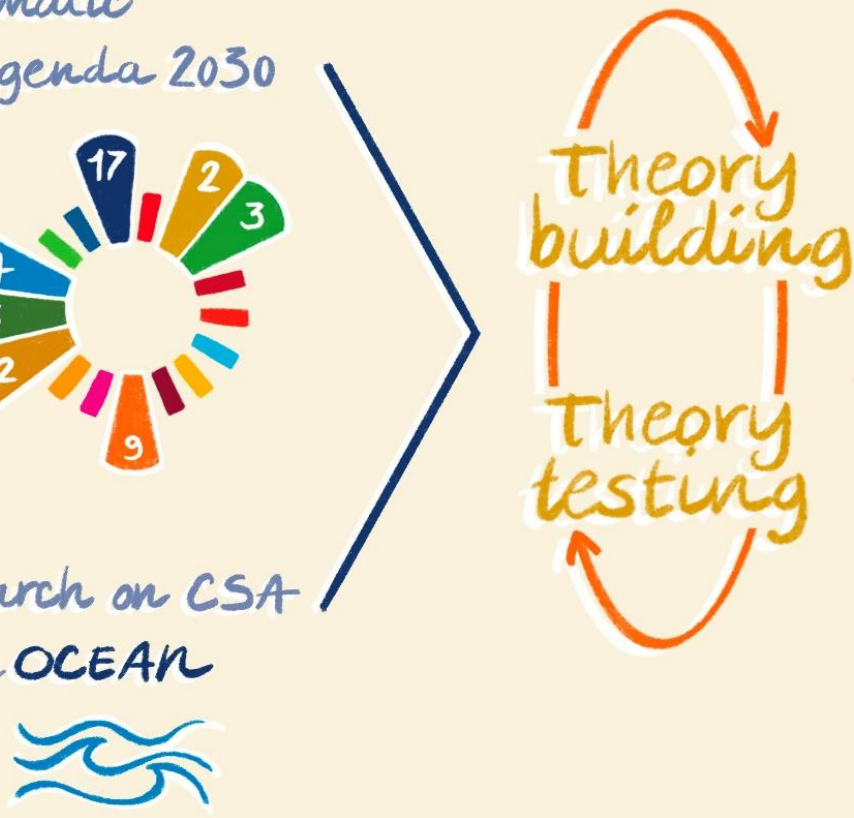

Figure 1. Illustration of the research.

\section{Materials and Methods}

\subsection{Theory Building}

The UN Agenda for Sustainable Development (Agenda 2030) [8] calls for coordinated and coherent policies and activities in implementing the seventeen Sustainable Development Goals (SDGs) endorsed 
by the UN global community. Writing in 2019, Schneider et al. enquire into the role of scientific research in responding to these societal demands [8].

Constructing a conceptual framework as a reading key for the interactions of the Agenda 2030 goals may serve as a starting point for scientific reflection. Translated to the domain of scientific legal research, this leads to the research question of the present contribution, which aims to establish how to engage systematically with the normative and legal dimensions of Agenda 2030, in particular the goals of achieving zero hunger by guaranteeing food security and good health for all (SDGs 2 and 3, respectively), while also protecting the environment and the ecosystem (SDGs 12,13,14), as well as promoting innovation (SDG 9), and strengthening partnerships among and for the goals (SDG 17).

The construction of such a conceptual framework has a twofold purpose: (1) It assists systematic mapping and critical analysis of multiple objectives of Agenda 2030; (2) It offers an approach for framing, implementing, and upscaling climate-smart practices. The two are in a mutually reinforcing relationship: a framework for the Agenda 2030 encourages the development of smart-solutions practices which, appropriately upscaled, have the merit of offering concrete solutions for achieving the SDGs.

Before embarking on the analysis of the implications of such systematic engagement, in this section I set the stage for the ensuing argumentation, presenting how the main research question on the need to find ways to engage systematically with the legal dimensions of the SDGs, and its practical implementations, generates four related research questions, on (1) the rationale for a systematic approach (why?); (2) the building blocks of a systematic approach and the implications for implementation (what? what actors, processes, and outcomes from a legal viewpoint?); (3) likely drawbacks and limitations to such way of proceeding (the obstacles); (4) the methodology involved (how to proceed?).

I begin by investigating the reasons why a systems approach to sustainability is needed (question 1). Elaborating further on a study conducted by Future Earth [9], I identify at least three areas of rationale for a systems approach [10]. First, the idea that changes in one part of the one-Earth support system [11] affect changes in all offers the opportunity for humanity to take charge of and responsibility for the systems by which they live [12]. Second, these changes are evident in the geographical and local-global spatial relationship: changes in one part of the world affect the whole [13]. Thirdly, there is the recognition that a systems approach has benefits also in terms of leveraging synergies and costs [14].

Conducting research on the conceptualization of the legal dimensions of the SDGs (in response to research question 2, on what?), should engage at least two levels of analysis. First, there is the need to identify and bring out the components and boundaries of each legal system involved-the structures, outcomes, and relationships that govern and inform the "SDGs grid", and presumably (but not limited to) the spheres of human rights law, food law, health law, and environmental law. Second, it is necessary to inquire how legal systems, as subsystems of a larger unit, interact with other subsystems (health science, food science, environmental science, for example) and contribute to the functionality of the larger system as a whole [15].

Such a theoretical approach is likely to have drawbacks, encounter obstacles, and produce some unintended consequences (question 3). Here I may note the difficulty of achieving a coherent level of decision-making and actions (where actions include research, innovation, policy, and management), because institutions, governance, and research funders are more often fragmented and siloed than integrated [16]; as well as the heavy dependence of a systematic approach on empiricism, entailing in-depth analysis of case studies from the legal domain and from other sub-systems. Especially regarding research, the temptation to slip comfortably into a mono-culture or mono-disciplinary approach is still present in legal studies. Therefore, the path of transitioning from mono- to inter-disciplinary (and therefore, systematic or systems-thinking) approaches remains fraught with obstacles and doubts [17].

In response to such obstacles, as explained by Lynn LoPucki [15], a systematic approach provides a conceptual framework for empirical analysis, and identifies the questions for empirical research [17]. This necessarily implies that a systematic approach without feedback from the empirical field of analysis risks sliding in the direction of a purely empty rhetorical exercise. To minimize such risk, the conceptual 
framework must be related to a project that, although in its preliminary stages, contains the promise of a climate-smart practice. The advantageous long-term effects of an appropriate correlation between conceptual frameworks and smart practices should be mutual: a conceptual framework that engages with the legal effects of sustainable developments needs to be verified empirically (through the testing of smart practices) and smart practices need a wider picture to be expanded, spread, and institutionalized by means of scaling-up strategies.

As an answer to question 4 (how?), I provide a brief critical appraisal of previous studies related to the current approach to systems thinking, noting how such development, after the necessary adaptations, can offer a solid conceptual basis for the further assessment of the need to engage systematically with the Agenda 2030 goals.

Before proceeding further, it is important to trace the history of systems thinking and provide some representative definitions from the field [18]. Here I focus only on critical analysis of some of its milestones.

The earliest roots of systems thinking are often—perhaps somewhat inaccurately-traced back to ancient Greek philosophy and abstract perspectives on the relations between a metaphysical unity, the whole, and its parts $[19,20]$. I find it helpful to bear in mind this concept of building blocks (unity, whole, and parts) and of their relationship, for understanding how a systems-thinking approach applied to law can ideally work.

Concerning the fundamental aspects of the contemporary systems-thinking approach, two main strands followed each other in the evolution of system theories and their application in research. Since the second half of the 20th century, two positions have emerged: the first supporting the idea that systems models are representations of the real world ("hard-system" thinking) [21-23], the second wave supporting the idea that subjectivity $[24,25]$ is a cornerstone of systems thinking, which entails the need to share and understand the perceptions and knowledge that the observers have of such models ("soft-system" thinking). Peter Checkland has pointed out how relevant it is to "tackle the real world as a soft system" [26,27] to solve complex situations generated by the interactions between different systems, capturing the subjective perceptions of such interaction rather than the interaction itself, thereby focusing on the relational link existing between the hard systems in the real world and the perceptions that researchers, and in general observers, have of them. Thus, the methodology develops from hard- to soft-systems thinking by building on shared understanding and knowledge, and participatory decision-making.

Such developments were central to the critical second wave of system thinking, benefiting from the narrative of dialogued participation and deliberative democracy in the discourse ethics of Jurgen Habermas $[28,29]$. The debate has been further developed by feminist systems theory that pushed the discourse towards the importance of giving voice to the "unvoiced" and the marginalized [30], and towards overcoming positivistic frameworks, challenging the ontological divide between humans and nature, and in general rejecting and overcoming dichotomy (gender dualism, subject-object dualisms, human-nature dualisms) [31]. One of the strongest points in feminist-system theory argumentation is that acknowledging difference and including continuity between humans and non-humans should be among the main objectives of a research methodology that aims to analyze, understand, and describe the constructs of complex systems.

After this simplified analysis of the evolution of the systems-thinking approach, we can turn to tackle the challenges that such approach may entail. Soft- and critical-system thinking, enriched by the elements of participation and deliberative democracy (Habermas) and by the inclusion of the unheard voices (as hinted by the feminist critical-systems thinking approach) regard systems as conceptual frameworks, thereby enabling cross-disciplinary dialoguing that can trigger creative changes. Whether and how such a conceptual framework can effectively work in practice, and (research question 3) help to unpack the legal implications of the SDGs, still needs to be clarified.

Martin Reynolds, a scholar of systems thinking, has correctly pointed out that there are at least three traps in the systems-thinking approach that may become evident in attempts at putting it 
into practice: (a) problem-solving (using the tools of the conceptual framework) risks leading to silo-solutions, inevitably associated with reductionism (first trap); (b) solving problems related to people and people's choices risks leading to dogmatism (second trap); (c) structuring the perception of the reality and reading such a dynamic through a purely systems-thinking approach may risk leading to the trap of fetishism (third trap) [32]. Before delving further into the challenges of a practical test for the conceptual framework, I offer some reflections on the conceptual framework of critical systems thinking applied to law, and its relationship with the legal dimensions of the SDGs.

\subsection{Theory Building in Law}

One of the mainstays in the application of systems thinking to law is the study conducted by Tomar Pierson-Brown [33], who provides the reader (and legal educators in general) with the basics of a lawyer-systems thinking approach. Here I summarize two aspects of her thought relevant for the purposes of this paper. First, the scholar sets up the framework of systems thinking by identifying its four tenets: (1) every outcome is the product of a structure; (2) the structures are interconnected, thus (3) they can be discerned; and (4) they are resilient and not fixed.

She then identifies at least two mental procedures for studying the legal phenomena through the lens of the result that literally "comes out" (the outcome) of a structure: surfacing and mind/process mapping. Both surfacing and mapping help to raise and consolidate awareness of the systemic context in which law-related problems emerge and are addressed [33].

Within this framework, the lawyer (a legal scholar, an attorney, or a law student) should then identify what factors are engaged in the production of such outcomes, how they are interconnected, and how such interconnection is perceived by the observers and therefore communicated to others. Pierson-Brown reminds us that also legal-systems thinking is a "soft" phenomenon (as described by Checkland), engaging critical legal analysis, where the perceptions of observers are central to reading and intervening in the creation and interpretation of the case solution. By providing concrete examples of how such methodology is implemented and applied to specific cases, Pierson-Brown also underscores how the activity of surfacing and mapping foregrounds the tension between the role of the individual and the role of the structure in determining and influencing behaviors. From the perspective of soft-systems thinking, this is reminiscent of the subjective dimension of the legal system, interlinking with what Gregory Todd Jones, another scholar of systems thinking applied to law, observes: interacting heterogeneous agents often display complicated behaviors that could not otherwise be predicted by studying the behaviors of the individual agents [34].

This observation seems to indicate that, in complex systems, a transformational process takes place, and consequently guides the understanding of the use that legal scholars can make of systems thinking: the importance of understanding networks, complex systems and non-linear dynamics can help in optimally designing institutions (e.g., law) that constrain human behaviors in ways that promote eco-social welfare. Thus, what Todd Jones adds to the debate on complex system theory is a reflection on how it can offer tangible guidance for institutional designers, where law is one possible institution [34].

The scope of the present contribution is slightly different from Jones's intentions: rather than searching for guidance for law designers, the focus of this study on critical systems thinking is on understanding how a critical-systems thinking approach applied to law (as one complex system relating to other complex systems) can interact with and contribute to achieving the Agenda 2030 goals on the one hand, as well as helping the scaling-up of smart practices. Thus, a more detailed answer to the "how" sub-question is offered here (how does systems thinking work when applied to law?) by proposing that blocks and objectives ("structures and outcomes", in the words of Pierson-Brown, "institutions" in the words of Todd Jones) be designed. Here the blocks are the food, health, environment, innovation and growth systems, and the objectives are the achievement of food security, good health, and environmental protection, through smart and innovative solutions. Devising laws that take account of such blocks and objectives and of their interactions can enable the 
conceptualization of climate-smart practices, supporting their eventual scaling up-and ultimately resulting in the achievement of interconnected SDG goals and broader socio-ecological welfare.

Naturally, such laws must deal with various aspects of each block: the actors involved in the interactions [35]; the principles and rules to be applied to certain processes; the processes; and the impacts of such processes on other institutions' scopes and objectives. In the next section, I present the climate-smart project SECURE, in its initial phase at the UiT The Arctic University of Norway, and how it touches on all the above-mentioned blocks and objectives, in turn calling for in-depth analysis and work in understanding and eventually redesigning the relevant legislation.

\subsection{Theory Testing: Case Study (SECURE)}

In January 2020, UiT The Arctic University of Norway agreed to fund an interdisciplinary project, "Novel Marine Resources for Food Security and Food Safety (SECURE)," for developing and applying an innovative approach to providing sustainable seafood, from marine raw materials, with health benefits for the fast-growing global population [36]. By contributing to policy dialogues and taking up complex governance issues related to the interaction between systems (national, regional, and international legal systems, as well as health, food, environment, and industry innovation systems), the projects aims to achieve better socioeconomic and ecological welfare, with an increase in the level of trust in seafood from environmentally conscious consumers [37]. Under the SECURE project, interdisciplinary research is conducted on the legal framework regarding the harvesting of new species, the composition of nutrients and contaminants in these raw materials, their effects on the oral and gut microbiome, on cardio-metabolic diseases and atherosclerosis and on the link between gut microbiota and atherosclerosis. Novel non-invasive tools will be introduced to study the development of atherosclerotic plaque, with the aim of enhancing the accuracy of atherosclerotic lesion characterization. Research results should enable targeted dietary advice.

The project can be seen as an example of climate-smart agriculture (CSA) applied to the ocean, with an original focus on fishers and food producers in the marine food industry, seeking ways to improve their productivity and incomes, as well as their adaptive capacity to climate change, by contributing to the mitigation of the greenhouse gas emissions (GHG) [38]. The three-pronged objectives of the CSA approach applicable to the ocean are: to increase fishers and marine food producers' productivity sustainably and improve their lifestyles and incomes; to strengthen resilience and adaptation to climate change; and to contribute to the reduction of GHG emissions.

In this vein, SECURE becomes a smart-ocean project aimed at achieving impacts on food, climate, health, and the oceans. Further, it should lead to assessment of how the advantageous practices promoted by the project could be replicated around the world and eventually scaled up [5]. Referring to the approach proposed by Renata Jagustovic et al. [5], it is possible already at this preliminary stage of SECURE to identify a matrix that can guide in the identification of elements that can be used in case of scaling up. Such elements build on the above-described pattern of surfacing, blocks or systems, outcome, relationships between blocks and outcomes, and perspectives from participants [39]. The surfacing implies the recognition of the "otherness" which, in the case of SECURE, translates into the identification of blocks (systems) that interact with each other (food, health, climate, innovation, and growth). This requires setting boundaries between what belongs to the system and what not. The blocks in themselves and their interaction entail identifying parts and wholes (such as achieving the SDG right "food for all" as a part of the food system; and achieving a satisfactory level of health for the growing population as a part of the overall health system). The relationship between the elements, defined as the connection between the block and the outcome, shows how systems are connected in multiple and complex ways, sometimes creating overlapping and contradictions between systems and outcomes. For instance, pursuing food security for all by creating new, sustainable sources from the sea can conflict with the need to protect the oceans from overharvesting and overfishing). Finally the element of participant perspectives assumes that any concept carries with it a frame of 
reference, and a perspective for viewing one concept (such as CSA) from a generic to more specific and subjective viewpoints.

\section{Results}

Investing critical-systems thinking as a conceptual approach to the SDGs brought two expected results: it contributed to theory building of a conceptual framework that could inform multidisciplinary research (in the field of environment, health, food, and law) in the identification of common and integrated solutions in the implementation of the Agenda 2030 on the one side; it showed the possibilities of upscaling successful climate-smart practices, as well as informing legal thinking on integrated socioeconomic and environmental objectives.

Adopting such a framework for understanding of CSA practices seems especially suited for thinking systematically in legal terms when relating to practices aimed achieving some of the goals of Agenda 2030 and fills a knowledge gap in the sense that it develops a framework applicable also to the ocean's health. Of course, the system will need to be tested-not only by researchers, but also among the addressees of the project, meaning the fishers, the food business operators, the local communities engaged, as well as the environmentally conscious consumers, and the actors in the healthcare system (givers and receivers). A legal model based on these premises can offer solutions to the need for upscaling, as well as to the need for systematically engaging with the achievement of multiple sustainable development goals.

\section{Discussion}

Taking to the extreme the position of feminist critical systems-thinking theory, thereby taking into account the unheard voices, might have some unexpected consequences that could rock the above-described conceptual framework on its foundations-or, perhaps, if correctly conducted, surprisingly solidify them. The "unheard" voice that I suggest taking account of is the ethics of living well, or buen vivir, promoted by indigenous peoples and Earth-allies around the world, and proposed by scholarship as a valid alternative to sustainable development, which inevitably contains within itself the dilemma and limits of growth and progress that obstruct efforts at environmental protection. Implicit in the dominant Western concept of "development" is the assumption of progress, that societies move forward in stages, and therefore that the earlier stages are "primitive and simple and emotional" [40]. The way forward, distancing from the "commodification and exploitation of life" perpetrated by the logic of capitalism and sovereignty over nature, will require radical transformative change. Such transformative change seems increasingly possible if based on a societal common effort grounded in indigenous knowledge, not capitalist development. The ethics of living well/buen vivir (BV) [41-44] must be recognized and promoted, with an open invitation to civil society everywhere to protect and promote indigenous rights and worldviews, respecting natural law, indigenous spirituality, and the values of reciprocity, harmony with nature, solidarity, and collectivity. The values of caring and sharing must be recognized as crucial in bringing about a fair and inclusive world.

As Nathalie Chassagne (2018) has pointed out:

$\mathrm{BV}$ is an evolving discourse with core principles that accepts the aims of SD [sustainable development], while seeking to "reshape the contours". The most fundamental differences between $\mathrm{SD}$ and $\mathrm{BV}$ are that the former is modeled on a system that values exponential economic growth as an indicator of wellbeing and within that is the notion that natural resources are commodities to be exploited and traded for profit; whereas the latter rejects both of these notions. Its contextuality and plurality are key strengths in translating BV into a community tool that promises to bridge the divide between indigenous worldview and modernity, filling the gaps where SD has failed. For environmental and social wellbeing there is no one size fits all model, it depends on context. [42].

Thus, the unheard voices from the supporters of the buen vivir ethics can be used as a critical lens for rethinking and reshaping the Agenda 2030 system, enriching the discourse with awareness of the need to overcome the dichotomy and imbalances of power: humans/non-humans, male/female, 
exploiters/exploited. Adjusting the trajectory towards the goals of Agenda 2030 may still be possible, if we can include the voices, cosmo-visions, and perspectives of indigenous and non-indigenous Earth-allies. They are indeed precious stones that have not yet been properly set in the crown of Agenda 2030.

\section{Conclusions}

This contribution has addressed the two main knowledge gaps at the intersection of the research on the Agenda 2030's goals (lack of a systematic mapping of the SDGs' interactions) and of the void in the study of climate-smart practices applied to the ocean. Developing a critical conceptual framework as a reading key for the SDGs' interactions (theory building) and exploring the possibilities of upscaling successful climate-smart practices, with the case study offered by the SECURE project (theory testing), are the two proposed methods to answer the research hypothesis on the validity and scope of conceptual frameworks for complex systems.

The application of a conceptual model for organizing the multiple goals of Agenda 2030 within a legal fabric to offer a context where climate-smart solutions and practices can blossom, multiply, and develop (also in ocean-related research) is a highly ambitious objective likely to require years of in-depth analyses and experimentation-as well as preparations for dealing with the shock-waves of success and failure. In addition comes the importance of constantly testing and rethinking the approach, responding to the changes and challenges encountered, starting from an evaluative analysis of alternative solutions, and listening sincerely to other voices.

Recasting the foundations of systems thinking towards the centrality of nature is essential in the readjustment process. The natural world does not always behave in ways that we humans can predict. As a living organism, it coevolves and changes at varying scales. Surely, it is time for us to use this opportunity to develop a better understanding of the natural world and its changes by deeply acknowledging, respecting, and attempting to restore the symbiotic relationship that we, as human beings, have with all the non-human others on this planet.

Funding: The legal research is funded by the Faculty of Law, UiT The Arctic University of Tromsø. The funds to cover publication costs are partly covered by the annum provided by the Faculty of Law to the author (proof-editing) and partly covered by UiT Publication Fund, UiT The Arctic University of Norway (publication fee).

Acknowledgments: The author is grateful to Edel O. Elvevoll and the SECURE research group for the comments on the early manuscript; to Susan Oivik for her precious work of editing and proof-reading; to the anonymous reviewer who said four times "yes" to the first draft (the power of positive thinking is so needed and yet so overlooked in academia); to the anonymous peer reviewers who suggested improvements (the soundness and clarity of this paper has greatly benefited from their suggestions, which included the insertion of a figure: drawings and colors are needed and overlooked in legal research); to Valentina Bongiovanni for her illustrated interpretation of this article (Figure 1; contact: bongiovanni.valentina@gmail.com).

Conflicts of Interest: The author declares no conflict of interest.

\section{References}

1. Hoegh-Guldberg, O.; Northrop, E.; Lubchenco, J. The ocean is key to achieving climate and societal goals. Science 2019, 365, 1372-1374. [CrossRef]

2. Arnberg, M.; Harlaug Refseth, G.; Pettersen, R.; Borch, T.; Dupont, S. Impact of Climate Change and Ocean Acidification on Ocean-Based Industries and Society in Norway, Observed and Future Impacts, Mitigation and Adaption Actions; Akvaplan-NIVA Report 61400-1, Norwegian Environment Agency Report: M-1632. 2020. Available online: https://www.miljodirektoratet.no/publikasjoner/2020/februar-2020/impactof-climate-change-and-ocean-acidification-on-ocean-based-industries-and-society-in-norway/ (accessed on 20 November 2020).

3. Available online: https://www.un.org/sustainabledevelopment/development-agenda/ (accessed on 26 October 2020). 
4. Adom, D.; Adu-Gyamfi, S.; Agyekum, K.; Ayarkwa, J.; Dwumah, P.; Abass, K.; Kissi, E.; Osei-Poku, P.; Obeng-Denteh, W. Theoretical and conceptual framework: Mandatory ingredients of a quality research. Int. J. Sci. Res. 2018, 7, 438-441.

5. Jagustović, R.; Zougmoré, R.B.; Kessler, A.; Coen, J.; Ritsema, C.J.; Keesstra, S.; Reynolds, M. Contribution of systems thinking and complex adaptive system attributes to sustainable food production: Example from a climate-smart village. Agric. Syst. 2019, 17, 65-75. [CrossRef]

6. Shapira, Z. 'I've got a theory paper-do you?' Conceptual, empirical, and theoretical contributions to knowledge in the organizational sciences. Organ. Sci. 2011, 22, 1312-1321. [CrossRef]

7. The First Hub of International Research and Communications Network Applied to the Ocean Is an Exception in This Regard, Even Though It Doesn't Seem to Focus on the Regulation of CSA for the Ocean: Credits to Elvevoll Edel, O. for This Indication. Available online: https://www.oceanpanel.org/ (accessed on 10 November 2020).

8. Schneider, F.; Kläy, A.; Zimmermann, A.B.; Buser, T.; Ingalls, M.; Messerli, P. How can science support the 2030 Agenda for Sustainable Development? Four tasks to tackle the normative dimension of sustainability. Sustain. Sci. 2019, 14, 1593-1604. [CrossRef]

9. For Further Information. Available online: https://futureearth.org/ (accessed on 26 October 2020).

10. Griggs, D. A Systems Approach: Imperative to Achieve the Sustainable Development Goals. 2019. Available online: https://futureearth.org/wp-content/uploads/2019/06/SDG-systems_issue-brief.pdf (accessed on 20 October 2020).

11. Young, O.R.; Steffen, W. The Earth System: Sustaining planetary life-support systems. In Principles of Ecosystem Stewardship; Folke, C., Kofinas, G., Chapin, F., Eds.; Springer: New York, NY, USA, 2009; pp. 295-315.

12. Leach, M.; Reyers, B.; Bai, X.; Brondizio, E.S.; Cook, C.; Díaz, S.; Espindola, G.; Scobie, M.; Stafford-Smith, M.; Subramanian, S.M. Equity and sustainability in the Anthropocene: A social-ecological systems perspective on their intertwined futures. Glob. Sustain. 2018, 1, e13. [CrossRef]

13. Bouyé, M.; Harmeling, S.; Schulz, N.S. Connecting the Dots: Elements for a Joined-Up Implementation of the 2030 Agenda and Paris Agreement. 2018. Available online: https://files.wri.org/s3fs-public/connectingthe-dots.pdf (accessed on 20 November 2020).

14. Griggs, D.; Nilsson, M.; Stevance, A.-S.; McCollum, D. (Eds.) For an in-depth analysis of a systematic approach to SDGs and its implications in terms of costs. In A Guide to SDG Interactions: From Science to Implementation; International Council for Science: Paris, France, 2017.

15. LoPucki, L.M. A systems approach to law. Cornell Law Rev. 1997, 82, 480-522.

16. Scharlemann, J.P.; Brock, R.C.; Balfour, N.; Brown, C.; Burgess, N.D.; Guth, M.K.; Ingram, D.J.; Lane, R.; Martin, J.G.; Wicander, S.; et al. Towards understanding interactions between Sustainable Development Goals: The role of environment-human linkages. Sustain. Sci. 2020, 1-12. [CrossRef]

17. Hargreaves, T.; Burgess, J. Pathways to Interdisciplinarity: A Technical Report Exploring Collaborative Interdisciplinary Working in the Transition Pathways Consortium; CSERGE Working Paper EDM 10-12; University of East Anglia: Norwich, UK, 2010; Available online: https://www.econstor.eu/handle/10419/48806 (accessed on 20 November 2020).

18. Jaradat, R.M. Complex system governance requires systems thinking-How to find systems thinkers. Int. J. Syst. Syst. Eng. 2015, 6, 53-70. [CrossRef]

19. Cohen, S.M. Aristotle's Metaphysics. In The Stanford Encyclopedia of Philosophy; Zalta, E.N., Ed.; Stanford University: Stanford, CA, USA, 2020; Available online: https://plato.stanford.edu/archives/fall2020/entries/ aristotle-metaphysics/ (accessed on 20 November 2020).

20. Ing, D. Rethinking system thinking: Learning and coevolving with the world. Syst. Res. Behav. Sci. $2013,30$. [CrossRef]

21. Checkland, P. The expression 'hard-systems' thinking did not exist until Checkland applied it in juxtaposition to 'soft systems' approaches. The development of systems thinking by systems practice. A methodology from an action research program. In Progress in Cybernetics and Systems Research; Trappl, R., Hanika, F., Eds.; Hemisphere: Washington, DC, USA, 1975; Volume 2, pp. 278-283.

22. Mingers, J. An idea ahead of its time: The history and development of soft systems methodology. Syst. Pract. Action Res. 2000, 13, 733-755. [CrossRef]

23. Valero-Silva, N. The philosophical foundations of critical systems thinking. In Critical Issues in Systems Theory and Practice; Ellis, K., Gregory, A., Mears-Young, B.R., Ragsdell, G., Eds.; Springer: Boston, MA, USA, 1995. 
24. Jackson, M.C. Critical system thinking and practice. Eur. J. Oper. Res. 2001, 128, 233-244. [CrossRef]

25. Midgley, G. What is this thing called critical systems thinking? In Critical Issues in Systems Theory and Practice; Ellis, K., Ellis, K., Gregory, A.J., Mears-Young, B.R., Ragsdell, G., Eds.; Plenum Press: New York, NY, USA, 1990; pp. 61-71.

26. Checkland, P.; Poulter, J. Soft systems methodology. In Systems Approaches to Making Change: A Practical Guide; Reynolds, M., Holwell, S., Eds.; Springer: London, UK, 2020.

27. Checkland, P. Systems Thinking, Systems Practice; Wiley: Chichester, UK, 1981.

28. Habermas, J. Discourse Ethics: Notes on a Program of Philosophical Justification; MIT Press: Cambridge, MA, USA, $1990 ;$ p. 65.

29. Habermas, J. The Theory of Communicative Action; Heinemann: London, UK, 1989; Volume 2.

30. Carant, J.B. Unheard voices: A critical discourse analysis of the Millennium Development Goals' evolution into the Sustainable Development Goals. Third World Q. 2017, 38, 16-41. [CrossRef]

31. Stephens, A. Describing a feminist-system theory. Syst. Res. Behav. Sci. 2010, 27, 553-566. [CrossRef]

32. Reynolds, M. Critical thinking and systems thinking: Towards a critical literacy for systems thinking in practice. In Critical Thinking; Horvath, C.P., Forte, J.M., Eds.; Nova Science Publishers: New York, NY, USA, 2011; pp. 37-68.

33. Pierson-Brown, T. (Systems) Thinking like a lawyer. In 26 Clinical Law Review; University of Pittsburgh Legal Studies Research Paper No. 2020-16; NYU School of Law: New York, NY, USA, 2020; pp. 515-562. Available online: https://ssrn.com/abstract=3574837 (accessed on 20 November 2020).

34. Todd Jones, G. Dynamical jurisprudence: Law as a complex system. Ga. State Univ. Law Rev. 2012, $24,873-883$. Available online: https://readingroom.law.gsu.edu/gsulr/vol24/iss4/6 (accessed on 20 November 2020).

35. Burns, T.R. The sociology of complex systems: An overview of actor-system-dynamics theory. World Futures 2006, 62, 411-440. [CrossRef]

36. Available online: https://uit.no/research/seafood/project?pid=667623 (accessed on 26 October 2020).

37. Dobscha, S. Women and the environment: Applying ecofeminism to environmentally-related consumption. In NA-Advances in Consumer Research; McAlister, L., Michael, L., Rothschild Provo, U.T., Eds.; Association for Consumer Research, University of Chicago Press: Chicago, IL, USA, 1993; Volume 20, pp. 36-40.

38. FAO Report, Climate-Smart Agriculture Case Studies 2018: Successful Approaches from Different Regions. 2018. Available online: http://www.fao.org/3/CA2386EN/ca2386en.pdf (accessed on 20 November 2020).

39. Cabrera, D.; Colosi, L. Distinctions, systems, relationships, and perspectives (DSRP): A theory of thinking and of things. Eval. Program Plan. 2008, 31, 311-317. [CrossRef]

40. Smith, L.T. Decolonizing Methodologies Research and Indigenous Peoples; Zed Books Ltd.: London, UK, 2008.

41. Thomson, B. Indigenous perspectives, buen vivir, sumaq kawsay and degrowth. Development 2011, 54, 448-454. [CrossRef]

42. Chassagne, N. Sustaining the 'Good Life': Buen Vivir as an alternative to sustainable development. Commun. Dev. J. 2019, 54, 482-500. [CrossRef]

43. Cubillo, A.P.; Hidalgo, A.L.; Domínguez, J.A. El pensamiento sobre el Buen Vivir. Entre el indigenismo, el socialismo y el postdesarrollismo. Rev. Clad Reforma Democr. 2014, 60, $27-58$.

44. Arcila Calderón, C.; Barranquero, A.; González Tanco, E. From media to Buen Vivir: Latin American approaches to indigenous communication de los medios al Buen Vivir: Enfoques latinoamericanos de la comunicación indígena das mídias ao Buen Vivir: Abordagens Latino-Americanas para a Comunicação Indígena. Commun. Theory 2018, 28, 180-201. [CrossRef]

Publisher's Note: MDPI stays neutral with regard to jurisdictional claims in published maps and institutional affiliations.

(C) 2020 by the author. Licensee MDPI, Basel, Switzerland. This article is an open access article distributed under the terms and conditions of the Creative Commons Attribution (CC BY) license (http://creativecommons.org/licenses/by/4.0/). 